\title{
Structure and management of the information required to predict the results of human interventions for environmental restoration after nuclear accidents
}

\author{
M. Moraleda, F. Claver, C. Vazquez and M. Montero
}

CIEMAT, Departamento de Impacto Ambiental de la Energia, Avd. Complutense 22, 28040 Madrid, Spain

\begin{abstract}
The decision about the best strategy to restore environments contaminated after nuclear accidents requires to assess accurately the effects of the contamination and the subsequent intervention. A Decision Support System, funded by the EU, has been developed in TEMAS project to analyse and optimise the intervention in complex scenarios. The evaluation methodology breaks down the scenario into basic units for which models describing the radionuclides behaviour and the intervention response are well established. It distinguishes among urban, agricultural and forest environments. Each one is divided into primary compartments (IE) attending to a hierarchical arrangement. This categorization leads to a database with relationships among the information groups (climate, uses, soil, crops and food chain, urban and forest configuration, population data...) through the attributes defining them. In this way, only a few inputs are necessary and the system selects and estimates the rest of parameters. Each IE is associated to different applicable countermeasures characterised in the database. The decision methodology calculates for each intervention cost, residual individual doses and averted collective dose. Finally, it selects the best strategy restricting the maximum annual individual dose and applying cost-effectiveness criteria to the collective averted dose. In this work the type and structure of the information managed in the evaluation module is presented as well as the schematic review of the decision module.
\end{abstract}

\section{INTRODUCTION}

TEMAS (Techniques and Management Strategies for Environmental Restoration) is a computerised tool to help in the decision about the best strategy to restore landscapes contaminated after nuclear accidents. This project was supported by the EU during the 4th Framework Program. TEMAS provides answer for complex scenarios including urban, agricultural and forest systems in the frame of the European Community. Several levels of contamination with different systems on each one could constitute the scenario for intervention.

The radiological impact is estimated through the ingestion pathway computing the fluxes of radionuclides till the products for consumption, taking into account specific diets for the different climatic regions and population groups. For the external dose the transference of energy from the deposition surfaces to the population is evaluated and different permanences are assigned depending on the population group and the use of the contaminated area. For each intervention option the following aspects (decision factors) are considered: cost, reduction of the radiological impact and secondary effects. For the decision about the best strategy the basic principles of radiological protection are applied in such a way that the maximum individual risk is restricted and cost-effectiveness criteria leads to a ranking of applicable interventions.

The information necessary to estimate the risk and the consequences of the interventions is structured in a series of tables according to the management requirements of the tool.

\section{SCENARIO CHARACTERIZATION}

The process of structuring whatever real scenario was hierarchically arranged following a set of information levels. The first level to identify the scenario is named Region, and the second one System. Regional differences in climate are related to differences in vegetation species, growing season date and 
cultural practices. Climatic conditions will also determine some aspects related to the exposition of the population to the contamination through the external irradiation pathway, since they mean different distribution population and permanence times. Four broad climatic categories can be distinguishable in the EU [1]: sub-Arctic taiga, Maritime, Continental and Mediterranean. Fifteen European countries have been selected, and each one is associated to a phytoclimatic region taking into account its geographical location. Then, the data from all countries associated to a specific region have been combined to obtain the respective representative value for that region. The second level of information, systems, is based on the human land use according to the CORINE land cover classification, [2]: Urban surfaces, Agricultural areas and Forest.

The evaluation methodology breaks down the contaminated scenario into a set of basic units for which models describing the radionuclides behaviour and the intervention response are well established. Each basic unit is associated to different applicable countermeasures.

Some general data are stored in the Temas database so all the evaluation models can access to it. It contains the data for the climatic regions, the distribution of population and physical data for each radionuclide. The classification of the ICRP [3] to define the number and the ranges of the age groups of concern has been selected. The population data for each European country have been collected from the International Database [4]. This information includes the mean demographic indicators and the population distribution by age intervals for each year.

\section{URBAN SCENARIOS}

For the external dose received by the population it is necessary to evaluate the radiological impact due to each deposition place on each representative location. This depends on the geometry and materials as well as on the habits of the population. The methodology is detailed in [5].

The Urban database contains the information needed for the urban evaluation model. The urban system is categorised in sub-environments having typical geometry. Each sub-environment is composed by a series of basic urban structures called components, with shapes, sizes and building materials well defined. On a component, the different areas where the contamination is deposited and where the intervention could be applied are called intervention elements (IE). Evaluation locations, indoor and outdoor, for the dosimetric evaluations $(E P)$ are also identified. In addition, the components are associated to different plausible uses.

The radiological impact is expressed as relative air kerma rates from each $\mathbb{E}$ calculated on the different EP placed in concentric evaluation regions $(C R)$ around the source and with different levels of resolution depending on the distance. For each $C R$ the number of components of each type is assigned. This information is the result of a series of Monte Carlo simulations described in [6]. A literature survey was made in order to compile available data on deposition of radionuclides on urban surfaces and subsequent natural reduction processes like weathering and migration of radionuclides in the ground From this data, relative effective source strengths of the different intervention elements after wet and dry depositions of caesium isotopes are assessed as a function of the time elapsed since deposition, and it can be expressed as a sum of two decreasing exponential functions with different half-lifes (source strength function), [6].

Related to each climatic region and type of sub-environment, population data over the different components-uses are stored in the tables collective permanences and individual permanences for the 6 age groups. The permanence times were estimated as annual average values. In [7] permanence times for the sub-environment "Row of Terrace Houses" in the Continental region were assumed. Slight variations were supposed for the other regions and sub-environments. Depending on the geometry adequate conversion factors from kerma to effective dose are used [8].

On each IE, one has to characterize the countermeasures that could be implemented. Some information is required: Description about the applicability of the countermeasure, how the technique must be implemented, equipment and operators needed, the scale of application...; the radiological efficiency expressed as a decontamination factor in case of removal of the contamination; cost factors in terms of manpower, consumables, investment or rent of equipment; and wastes generated characterised 
in terms of type, specific activity and volume per unit area of surface of intervention. The data were obtained from [9], [10], [11] and [12].

The real scenario of intervention is represented by one or more representative sub-environments, to which, real uses and representative deposition levels must be assigned; these are then named areas. The model calculates independently the contribution to the collective and individual doses on each EP/use receiver/population group due to the activity present on each IE/use emitter/applicable countermeasure of each area.

\section{AGRICULTURAL SCENARIOS}

For the impact evaluation in agricultural systems, models and parameter values for the transfer of radionuclides from the initial deposition on lands along food chains as well as data on consumption rates of foodstuffs and crop yields are needed, methodology presented in [13]. The different environmenta] compartments involved in the agricultural scenario have been structured in higher information levels named components (elemental unit) and are included in the Agricultural database. The information associated to each one is structured as follows:

The first categorisation is related with the land use. It uses the nomenclature from the second and third level of the CEC-CORINE Land Cover Map [2] and the FAO definitions [14]. Three broad categories of land use were identified: Arable lands, Permanent crops and Pastures. In the semi-natural systems, only the Unmanaged Grasslands are considered and together with the Pastures from agricultural systems were subsequently treated as a whole named Grazing system.

The primary component is the figure representing the contaminated plot and defined by the characteristics of the soil stratum and its qualitative and quantitative relationships with the crops or vegetal species growing on it (cropping pattern):

- Soil Compartment. The attributes defining the compartment are related with the physical and chemical characteristics of the concerned soil stratum that have influence on the behaviour of radionuclides. Attributes determining the availability of radionuclides to be retained by the soil matrix or be transferred to crops via root uptake (user inputs) are: Organic Matter, Texture, Exchangeable Ca, Exchangeable $K$. Secondary attributes, like Soil-solution Distribution Coefficient (default values from [15]), Field Capacity and Dry Bulk Density are inferred from these ones. Attributes conditioning the applicability of countermeasures are: Slope, Stoniness, Soil Depth and Soil Water Regime, Soil Disturbed and Crop on Grown.

- Vegetal Compartment. It represents the cropping pattern since the deposition date. They are defined by the characteristics from both the own species and cultivation management. Crops are grouped respect on the land use and are named using three identifiers, Group, Subgroup and Crop, based on the definition from FAO [16] and the Spanish Agricultural Statistic Yearbook [17]. Two additional identifiers connect the crops to the attributes of transfer: $I D \_R F$, retention for direct deposition according to FARMLAND, [18]; $I D \_T F$, transfer factors for agricultural systems, [19], and grazing systems, [20]. Crop intrinsic attributes, related with the species own characteristics influencing on the behaviour of the radionuclides in relation to the uptake and distribution among the different plant parts, are: Dry Matter Content, Top Fraction and Edible Fraction, Biomass along Time, Transpiration Ratio, Extractable Potassium, Optimum pH Range and Residual Biomass after Harvest. Different sources (especially [16]) were consulted to compile that information. In general, the mean value from all bibliographic sources has been assumed as default value (if lack of information the value for the more similar group is assumed). Some other attributes depend on the region such as: Sowing/Harvesting Dates ([21], [22], [23], [24], [25]; Total Fresh Yield ([14]) and Production Cost ([26], [27]). For the availability to transfer the radioactivity to the next components one considers: Interception Coefficient ([28]); Retention Factor from Direct Deposition ([29]); Ecological Removal Constant (involving mechanisms of leaching to soil deeper layer, root uptake and radioactive decay) and Soil-to-plant Transfer Factors ([19], [29], [30], [20], [31], [22], [15]).

The secondary component includes the transfer pathways along the food-chain associated to a primary component. A transference pathway represents the flow of radioactive contamination from a primary commodity (crop) to each processed product derived from it. The attributes characterising it are: 
a processing factor, a transfer factor and a regional utilisation factor. A distinction between vegetal and animal transfer pathway is made. The first one represents the processing for the harvested crop identified as the raw product of the primary compartment to a vegetal product. This product is classified into a fodder group, [32], according to their next destination: direct human consumption (group 0) or feedstuff (groups 1 to 5). The values for the attributes were obtained from [33], [16], [14]. The animal transfer pathway considers the processing of the feedstuffs through an intermediate compartment representing generic animal production systems in each european region to the final product for human consumption. The attributes of the pathway were calculated from the size and distribution of herd, the kind of product obtained, the annual productivity and the total ingestion rates and partition of feed according to the typical diets and the feeding calendar. Information for specific cases was available from [34], [35], [20] ,[25], [36], [37]. Data for the rest of parameters and climatic regions was obtained from [16]. Finally, all products for human consumption are classified into Dietary Groups.

The final component is the population. The age-dependent values, as committed effective dose equivalent per unit intake, were obtained from [3]. The consumption rates and the relative distribution of each product by age group were obtained from [14], [4] and [39].

The potential countermeasures considered were of two types: those modifying the availability of radionuclides in the root zone (mechanical countermeasures) and those causing modifications in the soilto-crop transfer (agrochemical countermeasures). The practicability of the countermeasures was assessed in terms of their technical feasibility, cost, effectiveness and secondary effects.

\section{FOREST SCENARIOS}

A specific model, [40], for the forest ecosystems is used for different subcategories of forest systems, deciduous and coniferous, located in temperate and boreal areas. The radioecological model has a compartimental structure of dynamic compartments. The data are stored in the Forest database.

The activity concentration along the time for each radionuclide in the different compartments and aggregated transfer factors to a specific forest product are taken from [40]. The contributions to the air kerma coming from soil layers at different depths was achieved from the location modification factors studied for the urban environment, [41].

The dosimetric model calculates individual doses due to the exposure pathways of ingestion of forest products, inhalation and external exposure during permanence in forest and doses coming from the wood industries (workers and public using wood products). Accumulation factors of the radionuclides during the wood processing were given by [42], [43].

A forest could be associated to different uses, recreational and/or wood exploitation. Population (public in general) affected by the contamination of the forest was taken from [40]. Finnish statistics were used to estimate the number of workers in a given forest activity. Conversion factors for the public, [38], and workers [42] for internal as well as for external irradiation are needed for each radionuclide. The dietary habits of the forest products are given for the six age groups considered.

An exhaustive study of the potential countermeasures was made. The main conclusion was that the remedial actions might rather be addressed toward the industrial processes, changes in the management system or the restriction on uses (consumption or permanence).

\section{DECISION MODULE}

Separate calculations of the doses received in each system are carried out by the evaluation model. For the decision about the intervention the global scenario is considered. The decision module is based on two main radiological protection criteria:

- To guarantee that unacceptable levels of individual risk are never reached.

- To reduce the collective risk to the population in an optimised way with regard to the social cost associated to the intervention. 
The first criterion requires controlling the individual dose to the critical group. Adequate reference levels of dose justifying the decision are required. The level of unacceptable individual radiological risk has been established in $100 \mathrm{mSv} \mathrm{y}^{-1}$ for the critical group of population (associated to a risk of serious deterministic effects). For the trivial radiological risk a value of $0,1 \mathrm{mSv} \mathrm{y}^{-1}$ was decided (related to the regional oscillations of doses that population receive because of the natural radiation).The second one leads to an optimisation of the remedial option applying cost-effectiveness criteria to the collective averted dose. Above the upper level, some intervention is always required and the criterion for the selection of options mainly concerns to the residual dose after intervention. Between the two levels the decision on intervention will depend on the result obtained applying the justification and optimisation principles. Averted collective doses using each applicable intervention option are compared to their associated social costs

\section{References}

[1] Wilkins, B.T.; Nisbet, A.F.; Woodman, R.F.M.; Burton, O. "The Selection of Agricultural and Grazing Scenarios for Use in TEMAS". TEMAS Deliverable-WP2. May 97.

[2] CORINE Land Cover. Commission of the European Communities, Luxembourg 1992.

[3] International Commission on Radiological Protection. "Age-dependent Doses to Members of the Public from Intakes of Radionuclides: Part I.” ICRP Publication 56. Ann. ICRP, 20(2). 1989.

[4] U.S. Census Bureau, The Office Statistic. "International Database. Summary Demographic Data".1998.

[5] Moraleda, M.; Vázquez, C.; Meckbach, R.; Müller, H. "TEMAS Project. Urban Model". CEMAT/GSF Report. CIEMAT/PPRI/51500/08-99. July 1999.

[6] R.Meckbach ."Urban Parameters". March 1997. Deliverable presented for TEMAS project.

[7] R.Meckbach, H.Müller, M.Moraleda. "Estimation of Uncertainties in the Urban Model Draft version". January 1999.

[8] Y.Tamaguchi. "Age-dependent effective doses for external photons". Rad.Prot.Dos. 55, 2 , pp 123, 1994.

[9] Roed, J., Anderson, K.G. and Prip H. "Practical Means for Decontamination 9 years after a Nuclear Accident”. Report RISO-R-828(EN). Riso National Laboratory, Roskilde, Denmark (1995).

[10] J.Brown, J.R.Cooper, J.A.Jones, L.Flaws, R.McGeary, J.Spooner. "Review of Decontamination and Clean-up Techniques for Use in the UK following Accidental Releases of Radioactivity to the Environment."NRPB-R288. 1996.

[11] Kasper G.Anderson. "Evaluation of Early Phase Nuclear Accident Clean-up Procedures for Nordic Residential Areas." NKS/EKO-5(96)18. RISO, 1996.

[12] "Contamination and Decontamination of Urban Areas." RISO, May 1993.

[13] C.Vázquez, M.Montero, M.Moraleda, F.Claver. "Methodology for Decision Making in Environmental Restoration after Nuclear Accidents: TEMAS System." Informe Técnico Ciemat. 2001 (in press).

[14] FAOSTAT Statistics Database. http://apps.fao.org/cgi-bin/nph-db.pl?subset=agriculture. (C FAO 9098

[15] International Atomic Energy Agency. "Handbook of Parameter Values for the Prediction of Radionuclide Transfer in Temperate Environments". Technical Reports Series No. 364. 1994.

[16] Statistical Agricultural Concepts. http://www.fao.org/waicent/faoinfo/economic/ESS. C FAO 199099

[17] Ministerio de Agricultura, Pesca y Alimentación. “Anuario de Estadística Agraria 1992”. Secretaría General Técnica, MAPA. Madrid. 1994.

[18] Brown, J.; Smith, J.G. "Database of Activity Concentrations of ${ }^{90} \mathrm{Sr}$ and ${ }^{137} \mathrm{Cs}$ in Foods and Animal Feeds to Aid Decisions on the Management of Crops and Animals Following an Accidental Release of Radioactivity to Atmosphere". NRPB, Chilton, Didcot, UK. TEMAS Deliverabie-WP2. 1998.

[19] Nisbet, A.F.; Woodman, R.F.M.; Haylock, R.G.E. "Recommended Soil-to-Plant Transfer Factors for Radiocaesium and Radiostrontium for Use in Arable Systems". NRPB-R304. 1998. 
[20] Burton, O. "TEMAS Grazing Systems Database. Soil-to-Grass Concentration Ratios for Radiocaesium". TEMAS Deliverable-WP2. 1999.

[21] Sinnaeve, J.; Gerber, G., Eds. "Underlying Data for Derived Emergency Reference Levels. Post. Chernobyl Action". Commission of the European Communities. EUR Report N. EUR 12553 EN. 1991.

[22] Müller, H.; Pröhl, G. "ECOSYS-87: A Dynamic Model for Assessing Radiological Consequences of Nuclear Accidents". Health Phys., 64(3): 232-252. 1993.

[23] Ministerio de Agricultura, Pesca y Alimentación. "Calendario de Siembra, Recolección y Comercialización". Año 1992. Tomo I. Secretaría General Técnica, MAPA. Madrid. 1993.

[24] Woodman, R.F.M.; Nisbet, A.F.; Penfold, J.S.S. "Options for the Management of Foodstuffs Contaminated as a Result of a Nuclear Accident". NRPB-R295. 1997.

[25] Nisbet, A.F.; Woodman, R.F.M.; Brown, J.; Smith J.G.; Wilkins, B.T. "Derivation of Working Levels for Animal Feedstuffs for Use in the Event of a Future Nuclear Accident". NRPB-R299.1998.

[26] Ministerio de Agricultura, Pesca y Alimentación. “Anuario de Estadística Agraria 1997”. Secretaría General Técnica, MAPYA. Madrid. 1999. ISBN: 84-491-335-5.

[27] European Commission. Directorate-General for Agriculture. "Agricultural Statistics". http://www.europa.eu.int/comm/dg06/agrista/table en/forew.htm. 1999.

[28] Brown, J.; Simmonds, J.R. "FARMLAND. A Dynamic Model for the Transfer of Radionuclides through Terrestrial Foodchains". NRPB-R273. National Radiological Protection Board, Chilton, Didcot, UK. 1995.

[29] Woodman, R.F.M.; Nisbet, A.F. “Transfer to Inedible Crop Parts. TEMAS Deliverable-WP2. 1998.

[30] Woodman, R.F.M.; Nisbet, A.F. "Transfer of Radiocaesium and Radiostrontium to Arable Fodder Crops". TEMAS Deliverable-WP2. 1998.

[31] International Union of Radioecology. "VIIIth Report of the Working Group. Soil-to-Plant Transfer Factors. Meeting in Madrid, Spain. June 1-3, 1992". IUR Pub R-9212-02. 1992.

[32] Lalonde, L.G. "LDPS ${ }^{2}$ Use's Guide". Animal Production and Health Division. Food and Agriculture Organisation of the United Nations. November, 1997.

[33] Green, N.; Wilkins, B.T. "Effects of Processing on Radionuclide Content of Foods: Derivation of Parameter Values for Use in Radiological Assessments". NRPB-M587. 1995.

[34] Burton, O. "Case Study of a Grazing Pasture". TEMAS Deliverable-WP2. Jul 1997

[35] Burton, O. "Case Study of a Grazing System Environment". TEMAS Deliverable-WP2. Jan 1998.

[36] Nisbet, A.F.; Woodman, R.F.M. "Typical Animal Diets in the UK”. TEMAS Deliverable-WP2. Aug 98.

[37] Green, N.; Woodman, R.F.M. "Recommended Transfer Factors from Feed to Animal Products". TEMAS Deliverable-WP2. Aug 1999.

[38] International Commission on Radiological Protection. "Age-dependent Doses to Members of the Public from Intake of Radionuclides: Part 2". ICRP Publication 67. Ann. ICRP, 23(2-3). 1993.

[39] Sinnaeve, J.; Gerber, G., Eds. "Underlying Data for Derived Emergency Reference Levels. PostChernobyl Action". Commission of the European Communities. EUR Report N. EUR 12553 EN. 1991.

[40] IAEA. "The IAEA Model for Aiding Decisions on Contaminated Forests and Forestry Products. Application to Intervention/Cleanup Criteria. (Working Material 99)". IAEA, Vienna, Austria. 1999.

[41] Meckbach, R. "Influence of the Depth Distribution of Radionuclides at Unpaved Areas on Air Kerma Rates in Urban Environments". February 1997. Deliverable presented for TEMAS project.

[42] Holm, E., Gäfvert, T. "Values for Model Parameters for Specific Forest Scenarios". TEMAS Deliverable-WP4. Feb 1999.

[43] Ravila, A., Holm, E. "Radioactive elements in the forest industry". The Science of the Total Environment 157, 1994, 339-356. 